\title{
Evolution of theoretical ecology in last decades: why did individual-based modelling emerge
}

\author{
Janusz Uchmański, Kamila Kowalczyk, Piotr Ogrodowczyk
}

Centre for Ecological Research, Polish Academy of Sciences, Dziekanów Leśny, 05-092 Łomianki, Poland

corresponding author, e-mail: januch@cbe-pan.pl

\begin{abstract}
Mathematical models of classical theoretical ecology are state variable models. They use density of population as a state variable. Because such models posses equilibrium states and they are stable around them, classical theoretical ecology has been dominated by considerations about stability of ecological systems. Three factors observed in ecology in last decades had great influence on the gradual decline of the classical theoretical ecology: first one is development of evolutionary ecology and the stress it laid on individuals, the second one nonequlibrium way of thinking about dynamics of ecological systems and the third one various methodological doubts about application of difference and differential equations in ecology. Individual-based modeling has emerged as the result of this discussions. However, individual-based approach to modeling the dynamics of ecological systems has natural tendency to describe particular systems and to produce their detailed models. Much should be done in the future to solve general problems formulated by classical theoretical ecology using method of individual-based approach.
\end{abstract}

Key words: classical theoretical ecology, computer simulation, difference equations, evolutionary ecology, mathematical models, species diversity, stability, spatial distribution.

\section{Introduction}

Application of mathematical models in ecology has long tradition. First attempts can be traced in biological literature as early as in the beginning of XX century (Kingsland 1995). Later it was so intensive, that so called theoretical ecology emerged between world wars with its well defined methods used for description of dynamics of ecological systems (Scudo \& Ziegler 1978). Theoretical ecology achieved the highest level of popularity in the seventies when the well known Robert May's book on relationship between complexity and stability of ecological system was published (May 1973) and in early eighties together with publication of the another May's book namely his famous Theoretical ecology (May 1981). From that time the interest in theoretical ecology has constantly declined and today we can say that the theoretical ecology in its classical form has quietly died. All attempts to revive the theoretical ecol- ogy in its classical forma (for instance see the third edition of Theoretical ecology (May \& McLean 2007)) are not able to introduce any new ideas. They only add unnecessary words to the old content. In the same time ecology constantly develops. Community ecology is a very good example. It is recently rapidly developing, but it uses completely different models.

Why the classical theoretical ecology disappeared? Why ordinary ecologists didn't even noticed this fact? Is that true that the classical theoretical ecology didn't leave any valuable traces in the ecology. Is it still possible to develop theoretical ecology? If the answer to this question is yes, what methods should be used now to ensure successful progress in newly formulated theoretical ecology? We will try to answer these questions. 


\section{Classical theoretical ecology}

Models of classical theoretical ecology describe dynamics of an ecological system consisting of $n$ species $(n=1$, $2, \ldots)$. They try to answer the question how the number of individuals in the population of each species will change in time. However, most often they describe not the number of individuals in the population but the population density the number of individuals in a unit of space. There are two basic assumptions of classical theoretical ecology: (1) classical models are state variable models; they assume that there exists a variable which fully describes the changes in population density; (2) this state variable is population density itself. The first assumption enabled classical ecology to use differential equations (or difference equations, if the time step is discrete) as mathematical tool very rich in sophisticated and powerful methods.

General form of classical model describing dynamics of an ecological system is given by following set of differential equations (they can be replaced by difference equations) (Murray 2002; Mangel 2006):

$$
\begin{aligned}
& d N_{1} / d t=f_{1}\left(N_{1}, N_{2}, \ldots, N_{n}\right) \\
& d N_{2} / d t=f_{2}\left(N_{1}, N_{2}, \ldots, N_{n}\right) \\
& \cdot \\
& \cdot \\
& d N_{n} / d t=f_{n}\left(N_{1}, N_{2}, \ldots, N_{n}\right)
\end{aligned}
$$

where: $N_{i}(i=1, \ldots, n)$ is the density of $i$-th population and $f_{i}$ is a function describing the influence of densities of all populations present in the ecological system on changes of the density of $i$-th population. Functions $f_{i}(i=1, \ldots, n)$ describe inter- and intraspecific interactions present in the ecological system.

Classical model describing dynamics of two competing species is of the form (Volterra 1931):

$$
\begin{aligned}
& d N / d t=r_{1}\left(1-N / K_{1}\right) N-\beta_{1} N M \\
& d M / d t=r_{2}\left(1-N / K_{2}\right) M-\beta_{2} N M
\end{aligned}
$$

where: $N$ and $M$ are densities of competing species, $r_{1}$ and $r_{2}$ - maximal growth rate of both populations not limited by any ecological interaction, $K_{1}$ and $K_{2}$ - carrying capacities or parameters related to equilibrium densities without interspecific competition, $\beta_{1}$ and $\beta_{2}$ - parameters describing the strength of interspecific competition.

Similarly classical predator-prey system can be described by the following set of equations:

$$
\begin{aligned}
& d N / d t=r_{1}\left(1-N / K_{1}\right) N-\alpha_{1} N P \\
& d P / d t=-r_{2} P+\alpha_{2} N P
\end{aligned}
$$

where: $N$ and $P$ are densities of prey and predator respectively, parameters $\alpha_{1}$ and $\alpha_{2}$ describe the intensity of predation.

\section{What we have learned from the classical theoretical ecology}

Classical theoretical ecology tried to answer most fundamental ecological questions, namely these which concern species diversity of ecological systems. What causes its increase, why it decreases? What are the long term tendencies in biodiversity changes? Why it seems to be persistent despite numerous different influences? Clear formulation of the ecological problem is always much easier when we decide to use mathematical methods than when we try to describe it verbally. It was true also in the case of classical theoretical ecology. The exact formulation of questions concerning dynamics of species diversity of ecological systems was possible in the frames of classical theoretical ecology. Additional, ecologists have been equipped with powerful tool to answer these questions - models applied in classical theoretical ecology.

However, tools we are using to analyze the nature, are not neutral. They influence the description we obtain. Differential and difference equation applied in classical theoretical ecology have been originally invented to describe physical processes. Difference and differential equations strongly supported the density-dependent approach which have been applied to understand the dynamics of ecological systems. Additionally they offer the possibility to analyze asymptotic behavior of the system, so its features after sufficiently long period. Most sets of differential and difference equations used in classical theoretical ecology possess equilibrium states and are stable in their neighborhood. This is the reason why classical theoretical ecology has been dominated by discussing stability of ecological systems. Classical theoretical ecology gave ecologist many arguments for equilibrium states of ecological systems and for stability of these systems locally or globally around these equilibrium states. Since the first formulation of classical models ecological systems have been treated as systems with equilibrium states, asymptotical stable and most often analyzed exactly in the state of equilibrium.

Roberts May's discussion of relation between complexity and stability of ecological systems can be a good example of achievements of classical theoretical ecology (May 1972, 1973, 1975). Analyzing properties of classical models in the above presented form with randomly chosen values of parameters he came to conclusion that ecological system consisting of $n$ species with average strength of interactions between them equal to $\alpha$ and with proportion $c$ of realized trophic connection as the fraction of all topologically possible is stable if: 


$$
\alpha(n c)^{1 / 2} \leq 1
$$

The above equations shows that a compromise between parameters included in it is necessary in order to achieve stability of the system. Ecological system with to many species, or to strongly interacting with each other can't be stable. On the other hand dividing system into isolated compartments stabilizes it.

Such results, as other more sophisticated achievements of the classical theoretical ecology, are intuitively plausible, but it is very difficult to prove them experimentally.

\section{Why did classical theoretical ecology abate?}

Two phenomena observed in last decades in ecology had great influence on the position of classical theoretical ecology: first one is development of evolutionary ecology, the second one nonequlibrium way of thinking about dynamics of ecological systems.

Development of molecular biology is the most characteristic feature of modern biology. Great progress in evolutionary biology has been also observed since the seventies. Mathematical models play an important role in evolutionary biology. However, evolutionary ecology never seriously treated models of classical theoretical ecology. Older publications invoked models of classical theoretical ecology only formally (see for instance Bulmer 1994), recently none even mention them (see Rice 2004). Especially important for the future of classical theoretical ecology was appearance of the theory of life histories evolution (Stearns 1992) and the behavioral ecology (Krebs \& Davies 1993). Both of them focus on individuals - on their features, strategies and behaviors. They deliver tools to describe and analyze interactions between individuals in the form of evolutionary game theory (Maynard Smith 1982; Hofbauer \& Sigmund 1990). Contrary to evolutionary ecology there are no individuals in classical theoretical ecology. Instead of them population density - average number of individuals in a unit of space - is the state variable in classical models. Evolutionary ecology has drawn attention of ecologist to individuals. Because evolutionary ecology explains diversity of individuals' features, for these ecologist, who were familiar with its achievements, the question whether population density properly describes all aspects of dynamics of ecological systems was quite natural. More general questions arose too - can we use state variable models to describe ecological systems which consist of so diverse individuals?

Ecological systems have been seen in classical theoretical ecology as stable systems staying in the equilibrium. This meaning still dominates in ecology despite stability has many meanings in ecology (Grimm \& Wissel 1997). However, recently one can observe that opposite view slowly spreads among ecologists' minds. Ecological systems can also be seen as nonequilibrium systems (Rhode 2005), because: (1) they posses in principle stable states, but due to various factors, they are far away from equilibrium condition for most of the time, or (2) they are really nonequilibrium - they have no equilibrium states or they are not stable. Formulation presented in point (1) allows to apply classical models, but formulation (2) doesn't. If ecological systems are really nonequilibrium ones there are no so far as we know biologically justified mathematical method to describe their dynamics. Despite very short history in ecology nonequilibrium approach to the dynamics of ecological system is able to produce interesting hypotheses concerning the nature of systems it describes. One of it states that species diversity of ecological systems exists due to repeated disturbances of the system, in the equilibrium states ecological systems are less diverse (Connell 1978, 1979).

Aside from evolutionary and nonequilibrium ecology also other questions mainly of methodological nature have been asked concerning the application of classical mathematical models in ecology. Differential and difference equations are mathematical tools invented to describe physical processes. Newtonian principles of mechanics fully justify use of state variables in equations describing motion of particles. But is state variable approach appropriate for biological systems? Will answer to this question be the same in the case of physiology and ecology for instance? And more general question: need we a new mathematical methods dedicated to biology and especially to ecology in order to describe dynamics of ecological systems?

All physical particles of a given type are identical and their features don't change in time. This is the reason why there are two equally good and giving the same results descriptions of the particle assembly in physics: in thermodynamics and in statistical physics. Individuals are "elementary particles" in ecology. Individuals in biology grow and develop. Their features change in time. Biological individuals are variable. They change as the result of interactions with other individuals of the same and different species. This is the reason why there are no two identical individuals even of the same sex and age. Do the population density properly generalized all these individual features in order to be a good state variable and to justify the use of state variable models. The answer is no. It is especially clear in the case of sedentary organisms, for instance terrestrial plants or even net spiders, so organisms with "semi-sedentary" stage in their life cycle. So called spatial effects are of special importance in the case of such organisms. The state of the individual depends on the states of its neighbours, on their sizes and distances to them. The spatial distribution of individuals plays very important role. 
The population density - the average number of individuals in a unit of space - says nothing about interactions with neighbours which influence fates of individuals. Probably only for populations of microorganisms - especially living in mixed water environments - the state variable approach using population density as the state variable is adequate. This was clear for Russian biologists in the first half of seventies (Romanovskij et al. 1975), but their books have not been read by western ecologists.

\section{Individual-based modeling}

So called individual-based approach to modeling of ecological system dynamics has emerged in the early nineties. It was the answer of all these ecologists who didn't fully believe that classical mathematical ecology offers good models to all questions stated above. Individual-based approach doesn't propose any given mathematical model appropriate for various natural systems. Rather different approach is proposed. Having in mind a given system, dynamics of which we would like to model, we try to describe the fates of individuals in this system and only from time to time we count individuals in the modeled populations. So dynamics of the number of individuals we obtain as a side product of modeling of individuals' growth, development and interactions between them.

Individual-based models are not analytical ones. Most often they are numerical models and results of them are obtained during computer simulations. However, because formula of individual-based approach is widely open, some models are also mixed ones, successfully combining analytical modeling (when they describe physiological processes like growth or development of individuals for instance) with computer simulations of other processes.

Individual-based models have numerous features different than features of models of classical mathematical ecology. They are individual-based (Uchmański \& Grimm 1996). It means that they describe growth and development of individuals. It is possible to include into them different equations or more complicated models of individuals' growth. Growth of not only unitary organisms can be described, but also of modular ones (Prusinkiewicz \& Lindenmayer 1990; Kaandorp 1994; Kaandorp \& Kübler 2001). Complex life cycles can be represented in individual-based models too. However, the most important feature of this kind of models is possibility to include mathematical description of different kinds of interactions between individuals. We are able to describe unequal resource portioning between competing individuals of the same animal specie (Uchmański 2000) or to describe intraspecific competition of terrestrial plants using for instance ZOI models (Hara 1988) or FON models (Berger $\&$ Hildenbrandt 2000). Interactions between individuals of different species can also be included into the individualbased models.

Individual-based models are pattern-oriented (Grimm et al. 1996). It means that there is no one universal model in individual-based approach to ecology like Lotka-Volterra model in classical theoretical ecology. We have to construct different models for different ecological groups of species: for terrestrial plants and sedentary animals, for planktonic plants, for plants with floating leaves, for planktonic animals and for many other. Patter-oriented means also constructions of individual-based models describing and explaining well defined ecological phenomena and mechanisms.

Individual-based models should be also spatially-explicit when spatial effects play an important role in the ecological system described by the model. Real spatial distribution of sedentary organisms can be explicitly introduced into the individual-based models and influence of neighbor individuals in relation with their size and distances modeled with this method. Classical theoretical ecology has never proposed any reasonable description of spatial interactions between sedentary organisms. For moving animals it can offer only annotation of classical equation with diffusion components (Czárán 1998). Diffusion equations as universal model describing spatial effects in ecological systems introduce hidden assumptions and are going to far simplification, while individual-based approach allows for realistic mathematical description of individuals' behavior in the space.

\section{Limitations of individual-based approach}

Ecological systems in nature consist of many species. Populations of these species consist of many individuals. Individuals of a given species are variable and their features are not constant in time and space. Is it possible to describe dynamics of such complicated systems using individual-based approach? Is it so that using this approach we face possibility of construction of numerous specific models and nothing else. No general conclusions will be possible. As result of this we will get lost in the growing number of details in the future. This is a real weak side of the individual-based modeling. However we believe that nature is "designed" in such a manner that some generalizations are possible. For instance to describe interactions between sedentary animals we can use the same mathematical descriptions as for terrestrial plants. Some methodological generalization are also possible in the individualbased approach. Recently Grimm et al. (2006) presented an attempt to formulate a standard protocol for construction of individual-based models in ecology. This is very useful proposition to canalize the thinking of ecologists about the systems they describe. Especially about the eco- 
logical processes which are important. If accepted it can also facilitate construction of mathematical tools - different pieces of mathematical description of which different models will be composed.

\section{Conclusions}

The individual-based approach has emerged as a new idea in ecology in the end of eighties and in the beginning of nineties. This process proceeded in different places partly separately and different reasons led ecologist to the conclusions about advantage of the individual-based approach over the classical one. First international conferences on individual-based approach in ecology took place in Warwick in 1998 and then in Knoxville in 1990 (DeAngelis \& Gross 1992). The next conference was organized in Mikołajki Hydrobiological Station in Poland in 1996 (Uchmański et al. 1999). The first book on this subject summarizing almost twenty years of development of individual-based approach in ecology was published by Grimm and Railsback in 2005 (Grimm \& Railsback 2005). There is entry "individualbased models" in Encyclopedia of Ecology (Grimm 2008). Many individual-based models have been constructed during this twenty years. Most of them describe very specific ecological situation. Many authors use the term individual-based but part of them don't understand it properly and deeply. As with many other new ideas it is in vogue to us the term and construct models and name them then individual-based ones. Nevertheless, we have the feeling that any fundamental problem of theoretical ecology have been solved using individual-based approach. Does it mean that good time for individual-based modeling has passed. Or we have still much to do to develop further individualbased approach in ecology and make it strong tool in the hands of ecologist.

\section{References}

Berger U. \& Hildenbrandt H., 2000, A new approach to spatially explicit modelling of forest dynamics: spacing, ageing and neighborhood competition of mangrove trees, Ecological Modelling 132: 287-302.

Bulmer M., 1994, Theoretical evolutionary ecology, Sinauer Associates, Sunderland.

Connel T., 1978, Diversity in tropical rain forest and coral reefs, Science 199: 1302-1309.

Connell T., 1979, Tropical rain forest and coral reefs as open non-equilibrium systems, Symposia of the British Ecological Society 20: $141-163$.

Czárán T., 1998, Spatiotemporal models of population and community dynamics, Chapman \& Hall, London-Weinheim.
DeAngelis D. L. \& Gross L. J. (eds.), 1992, Individual-based models and approaches in ecology: population, communities and ecosystems, Chapman \& Hall, New York.

Grimm V., 2008, Individual-based models, [in:] S. E. Jørgensen \& B. D. Fath (eds.), Elsevier, Oxford, Encyclopedia of ecology 3: 1959-1968.

Grimm V., Frank K., Jeltsch F., Brandl R. \& Uchmański J., 1996, Pattern-oriented modeling in population ecology, Sciences of Total Environment 183: 151-166.

Grimm V., Wissel C., 1997, Babel, or the ecological stability discussion: an inventory and analysis of terminology and a guide for avoiding confusion, Oecologia 109: $323-334$.

Grimm V. \& Railsback F., 2005, Individual-based modeling and ecology, Princeton University Press, Princeton-Oxford.

Grimm V., Berger U., Bastiansen F., Eliassen S., Ginot V., Giske J., Goss-Gustard J., Grand T., Heinz S. K., Huse G., Huth A., Jepsen J. U., Jørgensen C., Mooij W. M., Müller B., Pe'er G., Piou C., Railsback S. F., Robbins A. M., Robbins M. M., Rossmanith E., Rüger N., Strand E., Souissi S., Stillman R. A., Vabø R., Visser U. \& DeAngelis D. L., 2006, A standard protocol for describing individual-based and agent-based models, Ecological Modelling 198: 115-126.

Hara T., 1988, Dynamics of size structure in plant populations, Trends in Ecology and Evolution 3: 129-133.

Hofbauer J. \& Sigmund K., 1990, Evolutionary games and population dynamics, Cambridge University Press, Cambridge-London.

Kaandorp J. A., 1994, Fractal modeling. Growth and form in biology, Springer-Verlag, Berlin-Heidelberg.

Kaandorp J. A. \& Kübler J. E., 2001, The algorithmic beauty of seaweeds, sponges and corals, Springer-Verlag, Berlin-Heidelberg.

Kingsland S. E., 1995, Modeling nature. Episodes in the history of population ecology, The University of Chicago Press, Chicago-London.

Krebs J. R. \& Davies N. B., 1993, An introduction to behavioural ecology, Third edition, Blackwell Scientific Publishers, Oxford-London .

Mangel M., 2006, The theoretical biologist's toolbox. Quantitative methods for ecology and evolutionary biology, Cambridge University Press, Cambridge-New York.

May R. M., 1972, Will a large complex system be stable?, Nature 238: 413-414.

May R. M., 1973, The stability and complexity in model ecosystems, Princeton University Press, Princeton.

May R. M., 1975, Patterns of species abundance and diversity, [in:] M. L. Cody \& J. M. Diamond (eds.), Ecology and evolution of communities, The Belknap Press of Harvard University Press, Cambridge Mass.-London: $81-120$. 
May R. M. (ed.), 1981, Theoretical ecology. Principles and application, Blackwell, Oxford-London.

May R. M. \& McLean A., 2007, Theoretical ecology. Principles and applications, Third edition, Oxford University Press, Oxford-New York.

Maynard Smith J., 1992, Evolution and the theory of games, Cambridge University Press, Cambridge-London.

Murray J. D., 2002, Mathematical biology. I: An introduction, Springer-Verlag, Berlin-Heidelberg.

Prusinkiewicz P. \& Lindenmayer A., 1990, The algorithmic beauty of plant, Springer-Verlag, New York-Berlin.

Rice S. H., 2004, Evolutionary theory. Mathematical and conceptual foundations, Sinauer Associates, Sunderland.

Rhode K., 2005, Nonequilibrium ecology, Cambridge University Press, Cambridge-New York.

Romanovskij Y. M., Stiepanova N. V. \& Černavskij D. S., 1975, Matematičeskoje modelirovanije v biofizikie, Nauka, Moskwa.
Scudo F. M. \& Ziegler J. R., 1978, The golden age of theoretical ecology: 1923-1940, Lecture notes in biomathematics vol. 22, Springer-Verlag, Berlin-Heidelberg-New York.

Stearns S. C., 1992, The evolution of life histories, Oxford University Press, Oxford-New York.

Uchmański J., 2000, Resource partitioning among competing individuals and population persistence: an individual-based model, Ecological Modelling 131: 21-32.

Uchmański J. \& Grimm V., 1996, Individual-based modeling in ecology: what makes the difference?, Trends in Ecology and Evolution 11: 437-441.

Uchmański J., Aikman E. D., Wyszomirski T. \& Grimm V. (eds.), 1999, Individual-based modeling in ecology, Ecological Modelling 115, 2, 3 (special issue).

Volterra V., 1931, Leçons sur la théorie mathematique de la lutte pour la vie, Gauthier-Villars et $\mathrm{C}^{\mathrm{ie}}$, Paris. 